\title{
Negotiation of entitlement in proposal sequences
}

Post-print version of:

Asmuß, B. \& Oshima, S. Negotiation of Entitlement in Proposal Sequence. Discourse Studies 14(1): 67-86.

\section{Abstract}

Meetings are complex institutional events at which participants recurrently negotiate institutional roles, which are oriented to, renegotiated, and sometimes challenged. With a view to gaining further understanding of the ongoing negotiation of roles at meetings, this paper examines one specific recurring feature of meetings: the act of proposing future action. Based on microanalysis of video recordings of two-party strategy meetings, the study shows that participants orient to at least two aspects when making proposals: 1) the acceptance or rejection of the proposal; and 2) questions of entitlement: who is entitled to launch a proposal, and who is entitled to accept or reject it? The study argues that there is a close interrelation between questions of entitlement, aligning and affiliating moves, and the negotiation of institutional roles. The multimodal analysis also reveals the use of various embodied practices by participants for the local negotiation of entitlement and institutional roles.

Keywords: proposals, entitlement, affiliation, alignment, institutional roles, meetings, multimodality 


\section{Introduction}

Meetings, specifically business meetings, are formal encounters that are characterized by their pre-planned nature in terms of content, outcome, and participants (Asmuß and Svennevig, 2009). The pre-plannedness of meetings is often seen in relation to the various institutional roles of the participants, which are externally defined (meeting leader, superior, subordinate, and so on). Despite this pre-plannedness and stability of institutional roles, research has shown that meetings are complex institutional events during which the participants recurrently negotiate their individual positions. In other words, institutional roles are not static entities throughout the entire meeting event, but are recurrently oriented to, renegotiated, and sometimes also challenged (Boden, 1994; Deppermann et al., in press; Pomerantz and Denvir, 2007; Vöge, 2010). This paper further pursues the interactional negotiation of institutional roles by focusing on one recurrent activity in meeting talk, namely that of proposing a future action. Proposals in meetings can entail actions that will take place remotely outside the meeting; but they may also call for immediate actions to be implemented within the meeting (Houtkoop-Steenstra, 1987; Lindström, 1999). The present study focuses on the latter case, namely proposals that can be immediately fulfilled in the here and now. In all the cases on which the present study focuses, the proposal in question consists of a suggested change of wording in a specific text. However, proposals can take various linguistic forms.

\section{Excerpt (1)}

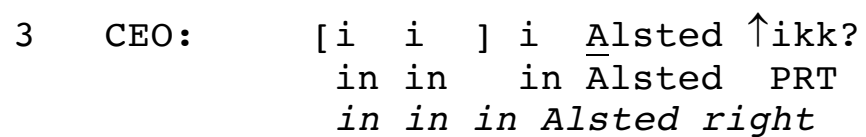




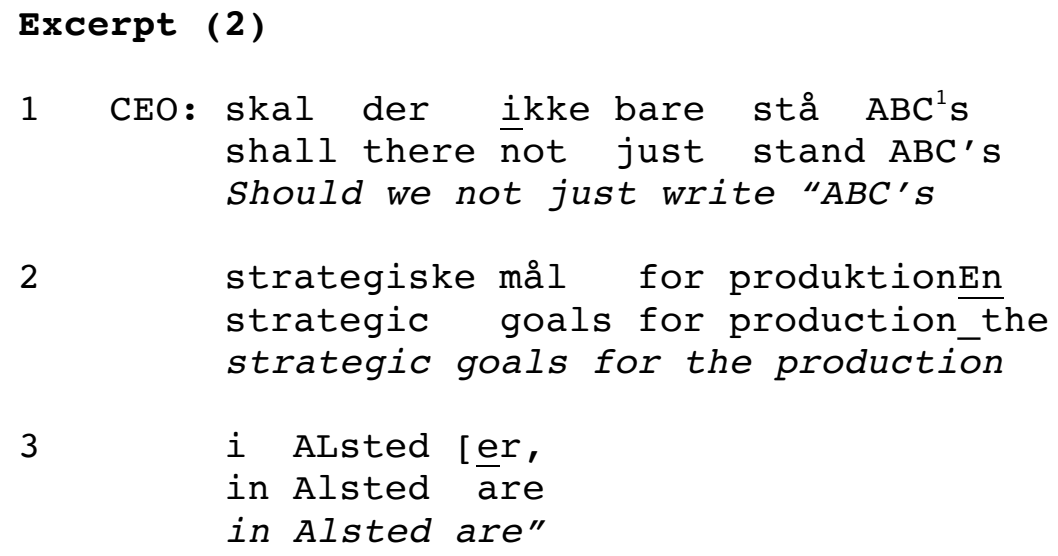

The excerpts shown above represent two main ways to present the proposal: a) just voicing the alternative formulation, as in excerpt (1); or b) by also making the action of proposing/suggesting explicit, as in excerpt (2). The linguistic form of proposals is also linked to this distinction. Proposals that make the action of proposing explicit tend to take the form of a yes-no question; whereas proposals that merely voice a solution to the problem take the form of phrases or sentences that are recognizable as alternative formulations to the formulations considered in the strategy document. The fact that social actions can be realized by various linguistic resources has been shown in various lines of research (e.g. Steensig and Drew, 2008 on questioning; Houtkoop-Steenstra, 1987; Maynard, 1984; Lindström, 2005 on proposals; Heinemann, 2009 on complaints; Curl and Drew, 2008 on requests); and the crucial aspect for unifying them as one social action lies in the fact that the co-participants orient to the first action despite its difference in linguistic form as performing the same action. Studies like these highlight the fact that what in terms of grammar appears to be different can turn out to perform the same social

\footnotetext{
${ }^{1} \mathrm{ABC}$ is the anonymized name of the company. All names and other indicators that might reveal the identity of the organization and its members are anonymized in the transcripts.
} 
action $^{2}$. As will be shown in sequential detail later in the analysis sections, the same seems to be the case for the proposals shown above: despite their different linguistic forms, the excerpts above propose a future action which makes an acceptance or rejection of the proposal relevant as the next action. However, the excerpts above also have some important differences. They differ in the degree of certainty regarding who is allowed to make a proposal and who is allowed to mark that the proposal will be accepted or not. In this paper, this phenomenon is referred to as entitlement, and we will elaborate further on it in section 3 .

The aim of this paper is to explore how participants in meetings, when making proposals such as those presented above, orient to (at least) two different aspects: acceptance or rejection of proposals and questions of entitlement. Making a proposal makes an acceptance or a rejection of the proposal conditionally relevant. But questions of entitlement are inherently related to questions of acceptance and non-acceptance of proposals: who is entitled to launch a proposal, and who is entitled to accept or reject it? In terms of alignment and affiliation, this multi-layeredness of proposals becomes crucial, as participants may choose to align and/or affiliate with the terms of entitlement while disaligning and/or disaffiliating with the proposal, and vice versa.

\section{Data}

The data for the study comes from a set of approximately eight hours of videotaped, twoparty strategy meetings in a medium-sized Danish company. The meetings involve the Chief Executive Officer (CEO) of the company and the Human Resource Manager (HR), and the aim of the meetings is to finalize a preliminary version of the company's strategy

\footnotetext{
2 Many of these studies also show that while performing the same action, the linguistic differences (i.e. the way in which the action is formatted) can influence the way the action comes across and is responded to.
} 
document. Prior to the meeting in focus here, various representatives of the upper management group commented in written form on the preliminary version of the document. These written comments are available to both participants in paper on the table, and are recurrently referred to during the meeting. Based on the comments, the participants engage in the activity of text editing, during which they go through proposal sequences to negotiate the change of wording in the strategy text. The activity of text editing entails the use of verbal, bodily and artefactual resources such as a computer and computer projection. Illustration 1 shows the set-up of the meeting:

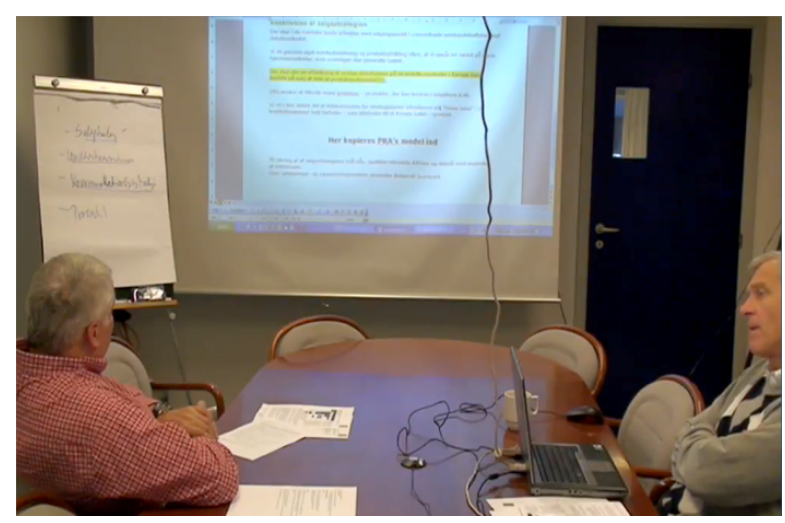

Illustration 1

The two participants - the CEO (hereafter CEO) and the HR manager (hereafter HR) are seated at a table (CEO on the left, HR on the right), with a whiteboard at the end of the room on which the screen from the notebook computer placed in front of HR is projected. Illustration 2 shows the triangular set-up of the situation in diagrammatic form: 


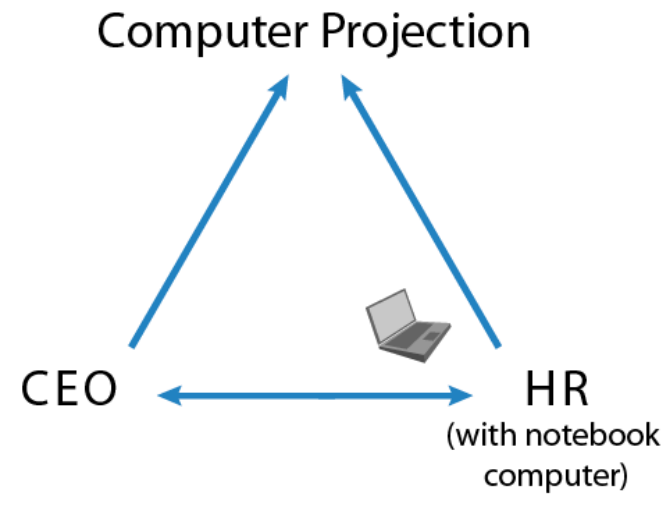

Illustration 2

CEO and HR orient individually or jointly to the computer projection, and they can also mutually or individually orient to each other. They have equal access to these resources. But not all the resources are equally available to the participants. HR is the one who has the notebook computer placed in front of him, and the screen from the notebook computer is projected onto the whiteboard. This means that HR is the one who actually makes any changes in the document on the computer, whereas the role of CEO is limited to suggesting and proposing changes. This is of relevance for the current study, where the participants make use of multimodal resources when negotiating the proposals (Stivers and Sidnell, 2005). When a CEO proposal is accepted by HR, it does not appear on the computer screen immediately. Instead, it takes HR's step-by-step physical actions (e.g. placing the cursor, deleting a word, typing, moving the cursor to the next paragraph, and so forth) to actually perform the change. The progress of these actions (how much he deletes, his typing speed, when to start typing, etc.) is visible on the computer projection, thus making it possible for $\mathrm{CEO}$ to monitor, attend to, and/or react to the changes in progress. 


\section{Proposals and entitlement}

In CA literature, the study of proposals has been rather scarce. One reason for this might be that - as Maynard 1984 puts it - "proposals are used to suggest a wide variety of actions" (Maynard, 1984: 80). Hence, in many cases proposals are treated as an umbrella term (Houtkoop-Steenstra, 1987) that covers various proposing actions like requests, offers, invitations and suggestions (Houtkoop-Steenstra, 1987: 62).

The works of Houtkoop-Steenstra (1987) and Maynard (1984) are the two most extensive CA studies on proposal sequences (but see also Lindström, 1997). Despite their different settings (Maynard in American plea bargaining, Houtkoop-Steenstra in everyday Dutch telephone conversations), they both see proposals as actions that make an acceptance or rejection $^{3}$ of the proposed item relevant as the next action, either immediately or remotely initiating action to carry out the proposed activity (HoutkoopSteenstra, 1987: 1; Maynard, 1984: 79). In other words, proposals are interactively constructed and locally occasioned in that the next action is shaped by and shapes the preceding action (Heritage, 1984; Nevile and Rendle-Short, 2009).

Some specific characteristics of proposals that have been studied are worth noting for the current study. In his study on plea bargaining, Maynard (1984) distinguishes between proposals (e.g. "DA3: How 'bout three months" in Maynard 1984: 79) and position reports (e.g. "DA1: I think she should be placed on probation and do jail time" in Maynard 1984: 82). According to him, a proposal is an utterance that suggests a solution

\footnotetext{
${ }^{3}$ In the literature, there is no common agreement on how the responsive action to a proposal should be referred to: whereas some refer to it as acceptance or rejection (Maynard, 1984; Houtkoop-Steenstra, 1987; Davidson, 1984), others prefer to talk about aligning or disaligning actions (Laakso and Tykkyläinen, 2009), or about agreement or disagreement (Heinemann, Mitchell and Buur, 2009; Nevile and Rendle-Short, 2009). The current paper seeks to contribute to the understanding of the nature of the next action by employing the notion of affiliation and alignment (Stivers, 2008).
} 
(see also Garcia, 1997: 225) and that thereby makes subsequent acceptance or rejection relevant. This is also the case in position reports; but what distinguishes proposals from position reports is that whereas the former are framed in a general form, the latter present proposed ideas as private or personal preferences or desires (Maynard, 1984: 81). Consequently, position reports often present downgraded or mitigated versions of proposals.

Houtkoop-Steenstra (1987) contributes to the study of proposals by focusing on how agreement is achieved in response to proposals. In terms of turn design, her study shows that - in line with classic findings on preference structure (Pomerantz, 1984) rejection is often delayed whereas acceptance is done straightaway (Houtkoop-Steenstra, 1987: 149; see also Oshima, 2009: 33f.). Houtkoop-Steenstra (1987) distinguishes between immediate and remote proposals. She points out that whereas it takes a three-part sequence to make an immediate proposal (proposal, acceptance, acknowledgement), remote proposals usually have a five-part structure (proposal, acceptance, request for confirmation, confirmation, acknowledgement). She argues that this might be due to the fact that immediate proposals can and should be complied with straightaway, whereas remote proposals do not initiate a direct next visible action (which could serve as a confirmation of the acceptance of the proposal). This aspect will be further pursued in our analysis of faceto-face interaction, such as how the display of confirmation of a proposal in immediate responses (which are the main instances found in our data) may lie in certain embodied actions (Streeck, 2002).

As indicated earlier, a proposal makes a specific next action relevant, namely that of accepting or rejecting the proposal. But apart from a clear rejection or acceptance of the proposal, our data also shows a participants' orientation to another aspect, namely how far 
the person launching a proposal actually have the institutional right or capacity to do so. We shall refer to this right or capacity as 'entitlement', and below we will outline the main line of research into this area.

Although the present study involves two participants with a hierarchical relationship (the CEO and the HR manager), it is not necessarily the case that CEO constantly appears as the more influential person over the activity of editing the document. The person proposing and implementing revisions to the text must be equipped with the right information (e.g., first-hand knowledge on the matter). Thus, CEO and HR constantly negotiate each other's right to propose revisions and to accept or reject proposals: once a proposal has been launched, the participants inevitably engage in the negotiation of entitlement. In other words, pre-established hierarchical relations between CEO and HR are sometimes rendered neutral by differential epistemic access to the informational and material resources that are required to implement the change in question.

Previous studies have shown that entitlement is not a predefined category, but that it is oriented to and negotiated by the participants in interaction through various linguistic means. In line with Lindström (2005), Curl and Drew (2008) argue that the distinction in designing a request displays the particpants' different degrees of entitlement and their understanding of contingencies of their requests. Following Curl and Drew's work, Craven and Potter (2010) further pursue the relationship between entitlement and features of local interactional context by focusing on the use of directives in mother-children interaction. As opposed to requests, the speaker's use of directives neglects the question of contingencies, making the relevant action compliance instead of acceptance. 
Accordingly, the speaker's entitlement is enhanced when the speaker treats the contingencies as the matter under his/her control.

We follow these studies and examine how entitlement is managed as a local and interactional practice. However, our aim is to also discuss the issue of entitlement in a specific context of an institutional setting: meetings. Indeed, the matter of entitlement becomes relevant and salient in workplace interactions, which involve participants with different roles and assigned tasks. For example, Heinemann (2006) looks at the home help service and argues that when making requests, care recipients display various degrees of entitlement through the use of positive and negative interrogative formats. Asmuß (2007) tackles the complex matter of entitlement at the workplace by examining the request sequence in public service encounters. She argues that the expectations of clients regarding public services are marked by the way in which they frame their requests. Both Heinemann and Asmuß find that negative interrogatives are used to mark the speaker's strong entitlement. Additionally, positive interrogatives (Heinemann, 2006) and pure statements (Asmuß, 2007) mark the speaker's low entitlement.

The studies done by Heinemann (2006) and Аsmuß (2007) indicate the significant tie between workplace interaction and entitlement, which we also intend to explore through the analysis of a business meeting. However, one feature that separates our study from the previous studies is the ambiguous characteristics of the roles and identities of the participants. In Heinemann's and Asmuß's studies, the roles of the participants were rather clearly defined and distinguished: care recipients make requests to home help assistants, and clients request information from public service counsellors. In other words, the action involving aspects of entitlement is produced by a certain participant only. In the present study, however, both CEO and HR recurrently launch proposals. Thus, the issue 
here is not only about one participant's entitlement. We also intend to investigate how the participants negotiate who is (or is not) entitled to do what.

\section{Analysis}

In what follows, we present three different sequential patterns of the proposal sequence. We begin our analysis by looking at a "clear-cut" example of a sequence in which a proposal is immediately accepted by the co-participant through both verbal and physical practices. Subsequently, two examples of post-expanded sequences will be examined, in which expansion gives room for the participants to renegotiate their entitlement to first launch and subsequently accept or reject the proposal. Finally, we analyze two excerpts in which the initial proposal is challenged by the co-participant's modified second proposal. Here, noticeably, apart from marking disagreement with the original proposal, the modified proposals serve as a resource to display the participants' understanding of the entitlement claimed by the original proposer.

Before moving onto our analysis, we would like to clarify the way we use some of the terminology in our analysis. Stivers (2008) introduced the distinction between "structural alignment" and "social affiliation" (31). Building further on this distinction, Steensig (in press) points out in terms of alignment that participants in interaction can cooperate on a structural level "by facilitating the proposed activity or sequence, accepting the presuppositions and terms of the proposed action or activity; and matching the formal design preference of the turn" (Steensig, in press). In other words, the response to the proposal is conditionally relevant in that it corresponds in structural terms with the initial proposal (Stivers, 2008). 
Apart from cooperating on the structural level (i.e. doing alignment), participants can also cooperate on the affiliative level (Stivers et al., in press, manuscript p. 25). Here, the speakers match the prior speaker's "evaluative stance" and "display empathy and/or cooperate with the preference of the prior action" (Stivers et al, in press, manuscript p. 26).

The distinction between alignment and affiliation makes it possible to distinguish between responsive actions to proposals: what level of action is addressed, and in which way? On a structural level, a responsive action can show alignment if it is type conform with the way the proposal is launched (e.g. producing a yes-no answer to a yes-no question) (Raymond, 2003), and/or if it accepts the interactional roles (or in our terms the entitlement) involved in the launching of a proposal, such as the roles of proposal teller and proposal recipient. On an affective level, the responsive action can affiliate by supporting the stance of the prior action and/or displaying empathy. In the proposal sequence, this may be shown by a speaker displaying his positive emotions toward the proposal that has been launched and/or the person making the proposal. In the following analysis, we refer to alignment and affiliation $^{4}$ as defined above as they become relevant in understanding various actions in relation to proposal sequences.

\subsection{Immediate acceptance of the proposal}

The analysis starts out by investigating a proposal sequence that consists of a first pair part consisting of the proposal and a second pair part consisting of the acceptance of the proposal. In the following excerpt, HR is typing a sentence in the strategy document, and he writes the word strategi ("strategy") twice, so he deletes the word directly afterwards in line 1 . While typing the sentence, he reads it aloud at a slow speed. In line 2 , he reads

\footnotetext{
${ }^{4}$ In the study we use the term "to comply with" to describe the physical act of following the proposal, which is usually done in this case by typing or deleting words on the computer.
} 
aloud er at ("are that") referring to the whole sentence that he has typed so far: strategiske mål for produktionsstrategien er at ("the aims for the production strategy are that").

\section{Excerpt (1)}

1 HR: ((types strategien (the strategy) and deletes thereafter strategien again))

2 HR: . hh [er at] ((HR reads this aloud from $\mathrm{CP})$ ) . hh are that

In overlap with HR saying er at ("are that), CEO comes in with a proposal for an insertion:

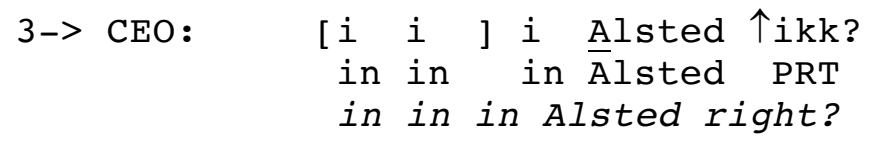

CEO proposes that the specific production site, namely Alsted, should be included after produktionsstrategien ("the production strategy") and before er at ("are that"). It is interesting to consider the form of this proposal - a statement ending with a tag - more closely. The way it is produced indicates that CEO does not regard it as problematic: it is launched without any hesitation, pauses, or other markers ${ }^{5}$. While CEO's proposal makes HR's acceptance or rejection of the proposal the next relevant action, the way CEO's proposal is designed also shows his entitlement with regard to making the proposal. In other words, by using a direct statement CEO shows that he is entitled to make the proposal, and by ending it with the tag $i k k$ ("right"), which indicates low contingency, he makes an acceptance of the proposal by the co-participant the next preferred action. HR promptly accepts the proposal, thereby ratifying his co-participant's claim to entitlement:

\footnotetext{
${ }^{5}$ All of these practices could indicate upcoming problems (Pomerantz 1984).
} 


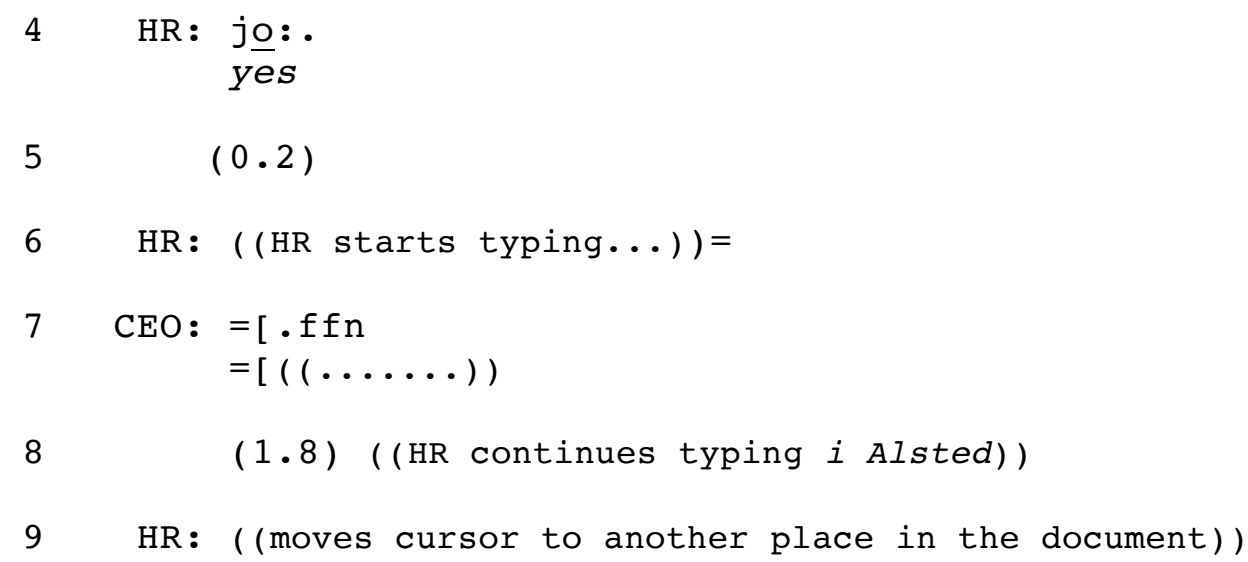

In line 4, HR accepts the proposal straightaway by aligning (i.e. by giving a type-conform answer on a structural level) and by complying (i.e. typing in 1. 6). Note that in line 9 it is HR who marks the completion of the proposal sequence by moving the cursor to a new place in the document. This excerpt shows a proposal that is granted straightaway by a combination of verbal and embodied actions. There is no disagreement about: 1) who is entitled to make the proposal; 2) who is entitled to grant the proposal; or 3) who is entitled to mark that the proposal has now been granted, thus marking sequence completion. In short, the participants solve the problem entailed in the proposal without any problems: either regarding what the proposal is about, or regarding questions of entitlement.

\subsection{Post-expansions and negotiation of entitlement}

As in the excerpt above, the participants in the next two examples also quickly reach agreement regarding the initial proposal. However, what sets the following excerpts apart from the previous one is that they are followed by post-expansions.

The following segment takes place shortly after excerpt (1), with the two participants returning to a discussion of the strategic goals of the production strategy. Here, CEO proposes a change in wording from produktionsstrategi ("production 
strategy") to produktionen ("the production"), thereby deleting the word strategi

("strategy").

Excerpt (2)

1 CEO: skal der ikke bare stå ABCs

shall there not just stand $A B C$ 's

Should we not just write $A B C^{\prime} s$

2

strategiske mål for produktionEn

strategic goals for production the

strategic goals for the production

3 i Alsted [er,

in Alsted are

in Alsted are

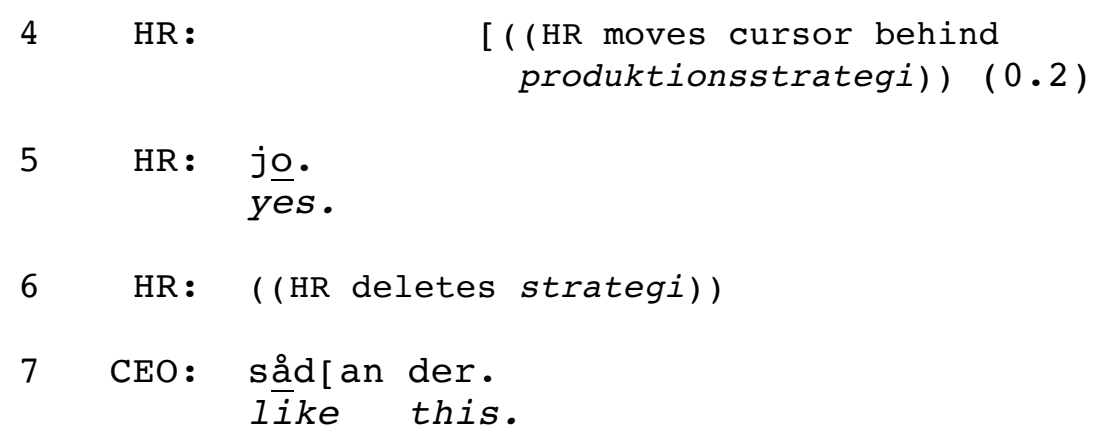

In lines 1-3, CEO proposes a change in the wording of the strategy text. He does so by using a question format that makes a yes-no acceptance or rejection of the proposal relevant. While the format of his proposal indicates CEO's low entitlement (as seen in his use of skal (“shall”)), it clearly marks HR's acceptance as the next preferred action. The use of the negative interrogative $i k k e$ ("not") indicates low contingency, expressing a strong expectation that the alternative formulation will be accepted, and the use of the particle bare ("just") indicates that this is a minor change that does not make any substantial difference and that it should not prevent the co-participant from accepting the proposal. As a response, HR first performs an embodied action indicating a first step into acceptance of the proposal by showing his understanding of the location of the problem (1. 
4). Thereafter, HR provides a verbal acknowledgement of the proposal (1. 5) and performs the first part of the proposed action by deleting the word strategi ("strategy") (1. 6), which is followed by CEO's utterance that marks sequence closure (1. 7) (see Lindström \& Heinemann, 2009 for the use of "sådan" at sequence closure). Still, for HR to fully comply with the proposal, he must add the definite article en ("the") ${ }^{6}(1.8)$. In other words, CEO marks a sequence completion through talk before the proposal is fully implemented. As CEO moves the sequence forward (most likely to its closure), HR produces a post-expansion of the sequence:

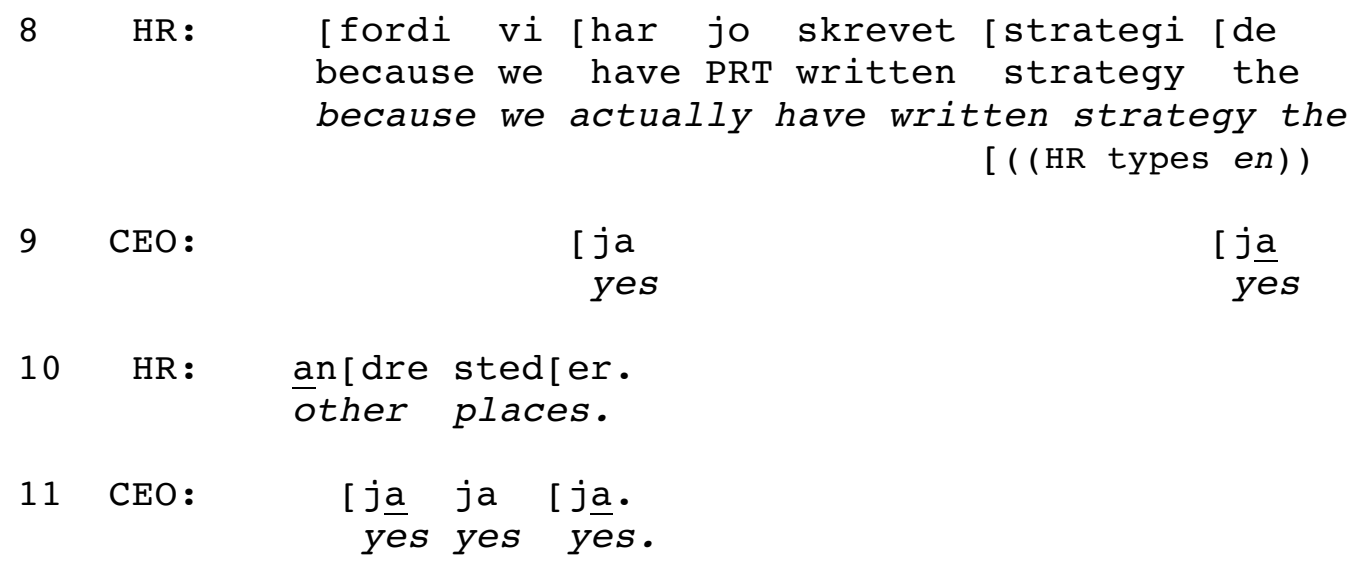

As seen above, HR expands the sequence with an account, thereby providing his own reasoning regarding the need for the change (11. 8 and 10); and in doing this he completes the process of compliance by typing en ("the") in line 8 . This post-expansion demonstrates HR's competence regarding his individual judgment of the proposal, and thereby his authentic agreement. If he had simply oriented to CEO's proposal as a change that needs to be accepted, and if he had oriented to his role as a mere typist, he would not have had to demonstrate his independent judgment regarding CEO's proposal.

Nonetheless, he claims his entitlement to judge and accept the proposal, thus enacting the

\footnotetext{
${ }^{6}$ In Danish, definite articles are affixed to nouns.
} 
role of co-discussant. The following excerpt shows another case in which the negotiation about entitlement coincides with the enactment of specific institutional roles.

Here, the proposal launched is about the wording change: from intranettet skal vare ("the intranet shall be") to intranettet er ("the intranet is").

\section{Excerpt (3)}

1 HR: Der har jeg skrevet at intra[nettet sThere have I written that intranet_the sThere I have written that the intranet s-

[ ( ( HR moves cursor behind skal være))

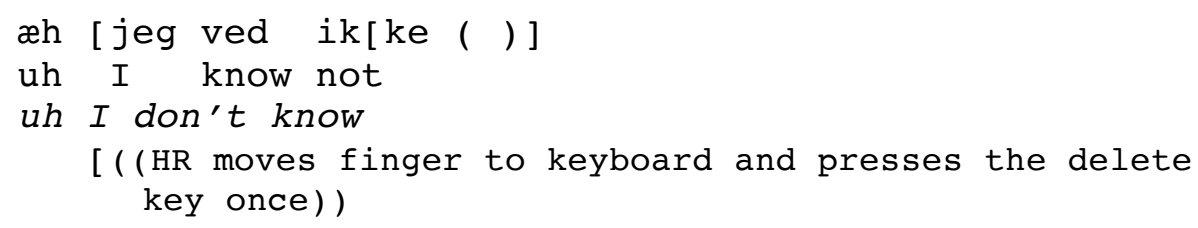

In lines 1-2, HR proposes a possible problem with the use of skal vare ("shall be") already written in the document. He locates the source of the problem precisely by cutting himself off before the problematic wording ("s-"), and also by locating the cursor behind it (i.e. behind skal vare ("shall be")). However, he ensures that there is room to discuss possible solutions by immediately saying "jeg ved ikke" ("I don't know"). At this point, he also makes a rather ambiguous bodily action of hitting the delete key once. His verbal and bodily actions may be an indication that he does not have a solution, that he is performing a word-search, or that he is not entitled to produce the solution alone (provided that he actually has one). But whatever the truth of the matter, his actions invite CEO to engage in the discussion and/or proposal of a possible solution to the problem.

Then, CEO makes a proposal for change (1. 3), but his turn starts abruptly and is uttered rather loudly, marking it as an interruption. In other words, his turn is shaped 
independently, ignoring the "firstness" of HR's turn. In so doing, CEO creates an epistemic hierarchy between himself and HR: HR did not know the proper solution, but CEO did know the problem and the proper solution. CEO's choice of formatting the proposal in the form of a direct statement emphasizes this epistemic hierarchy, and marks his orientation to his own entitlement in making the proposal (as opposed to marking lower entitlement by using practices such as questioning, mitigating, try-marking, etc.) However, we need to keep in mind that HR's invitation to contribute by doing a word search in line 2 also provides CEO with the entitlement to make a suggestion. Now the solution has been provided, the sequence could be completed at this point if HR accepted the entitlement claimed by CEO. But this is not done here. Let us see how HR deals with the strong entitlement claimed by CEO. He ignores CEO's utterance by proposing his own solution, as seen below.

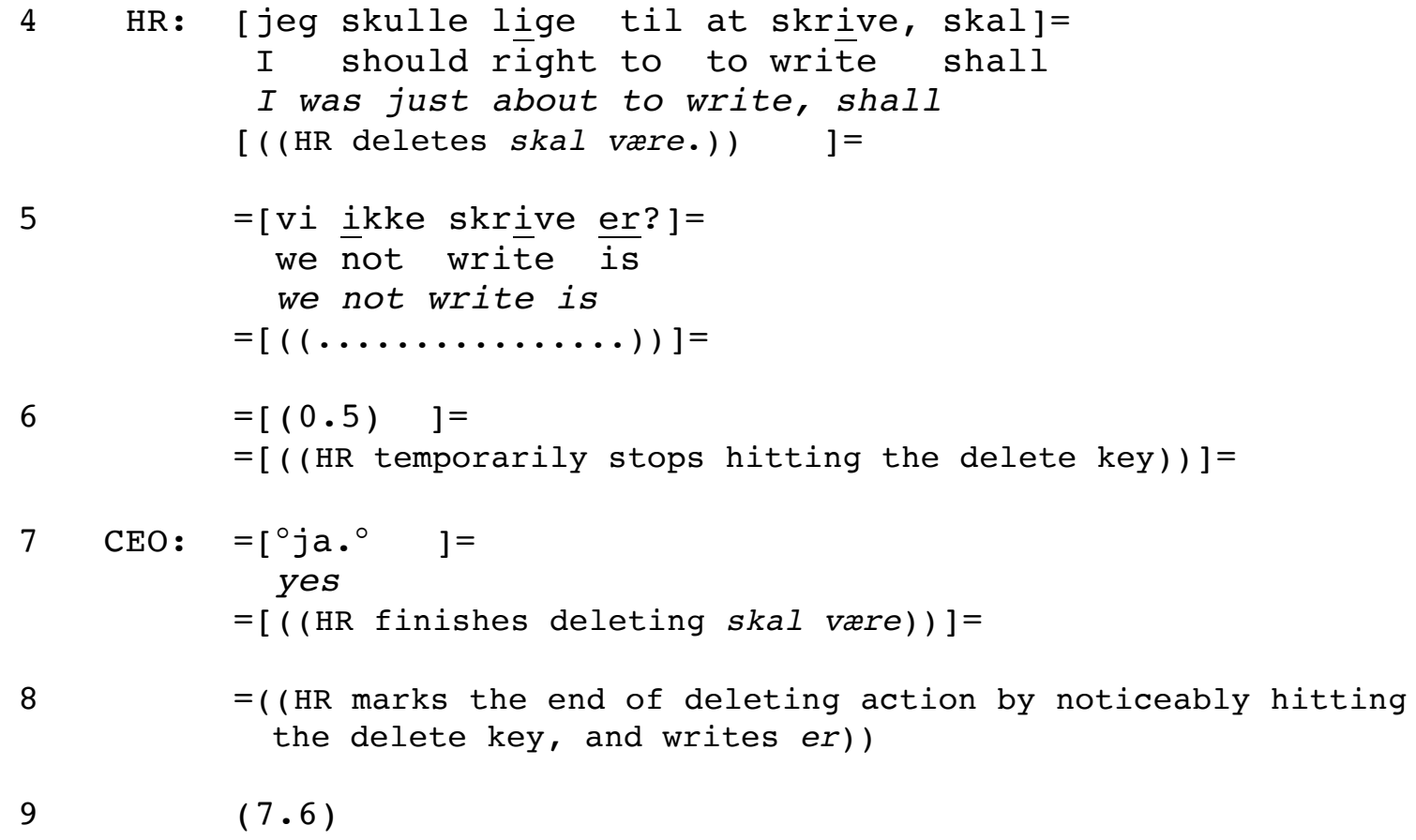


Upon CEO's overlapping but absolutely audible correction, HR relaunches the sequence by commenting on the fact that he was about to make a proposal for the solution (11. 4-5). The solution is identical to CEO's proposal, but HR presents it as his “autonomous" idea. HR's embodied actions of delaying the typing process also contribute to this framing. In lines $4-5$ he starts deleting skal vare ("shall be") as he proposes the solution by repeatedly hitting the delete key. If he were to orient to CEO's earlier proposal made in line 3, he could have typed er ("is") immediately following the action of deleting (1. 5, 6 or 7). However, he does not do so until CEO acknowledges HR's proposal in line 7. In fact, HR momentarily delays the action of deleting skal vare ("shall be") in line 6 , and finishes the deleting process only after CEO agrees with HR's proposal in line 7. He then completes the revision by typing er ("is") following CEO's confirmation. Here, HR's well-timed arrangement of physical actions serves to maintain the solution as "his own", which needs a co-participant's agreement before its implementation. In this way HR reconstructs his entitlement, which had been diminished by the design of CEO's proposal. Through the expanded sequence, HR not only reestablishes his position as the proposal initiator, but also reframes the proper solution to the problem as his own.

The examples outlined above are taken from a set of cases in which the participants renegotiated their entitlement and institutional roles by extending the proposal sequence. The sequence expansion was not used to negotiate the content of the proposal per se, but to negotiate entitlement. Thus, as soon as HR found a way to solve this problem (i.e. claiming or reclaiming his entitlement by presenting the account or solution as his own), the sequence was brought to a closure, and the proposal - whether it belonged to CEO or HR - was agreed upon and implemented. But what if the actual content of the initial proposal is problematic? How do the participants deal with the issue of entitlement then? This will be the focus in the following section. 


\subsection{Modified second proposals and renegotiation of entitlement}

Our last set of analysis presents two examples in which the proposals are not accepted straightaway, but are met by modified second proposals launched by the other speaker. These modified second proposals not only question the correctness of the initial proposals, but also show an orientation towards questions of entitlement. More specifically, the way a co-participant's modified second proposal is launched displays his understanding of the entitlement entailed in the original proposal.

In the following segment, the two meeting participants discuss the communication strategy. They talk about which media are most prominent in the external communication of the company. CEO proposes the addition of a new word, foretrukne ("preferred") to ABCs anvendte medium (“ABC's applied medium”). HR promptly aligns with CEO's action, but then proposes a modification to the new word.

\section{Excerpt (4)}

10 CEO: mt skal vi skrive foretrukkent (0.8) an[vendte?

mt shall we write preferably applied

mt shall we write "preferably applied"?

[ ( (CEO looks at HR ) )

12 HR: j[… yes.

[( (HR moves cursor in front of anvendte))

$$
(1.0)
$$

14 CEO: fordi: vi skriver også lidt [andet jo. because we write also little $\overline{d i f f e r e n t ~ P R T . ~}$ Because we actually also publish a few other things. 
16 HR: ${ }^{\circ} \mathrm{ja}{ }^{\circ}$.

yes.

17

$$
(0.2)
$$

In line 10 CEO makes a proposal, but his utterance does not simply solicit a confirmed response from HR. Rather, it makes relevant HR's action of stating an opinion as a co-discussant, as seen in: 1) CEO uses skal vi ("shall we"), with which he orients to the equal entitlement between him and HR; and 2) during his utterance, CEO makes a recognizable gaze shift from the screen to HR, which invites HR to establish a mutual gaze and thus possibly suspend typing to engage in the discussion.

HR aligns with CEO's turn structure by firmly saying $J a$ ("Yes") (1. 12). At the same time, he also moves the cursor in front of anvendte ("applied"), which indicates an upcoming edit of the sentence under discussion. While HR's actions here apparently show his compliance with CEO's proposal, they do not orient to the equal entitlement between CEO and HR made relevant by CEO's utterance. HR provides a minimum (perhaps overhasty) acknowledgement without establishing mutual gaze, thereby refraining from affiliating with CEO's stance that he and HR are co-discussants. Rather, HR simply treats CEO's utterance as an instruction-like proposal that needs to be implemented. CEO then provides an account of his proposal (1. 14), possibly fishing for affiliative actions from HR. Once again, HR only responds with a delayed, minimum response (1. 16). Asmuß (in press) argues that the lack of affiliative moves can project an upcoming disagreement, which also seems to be the case here, as seen in HR's subsequent modified proposal.

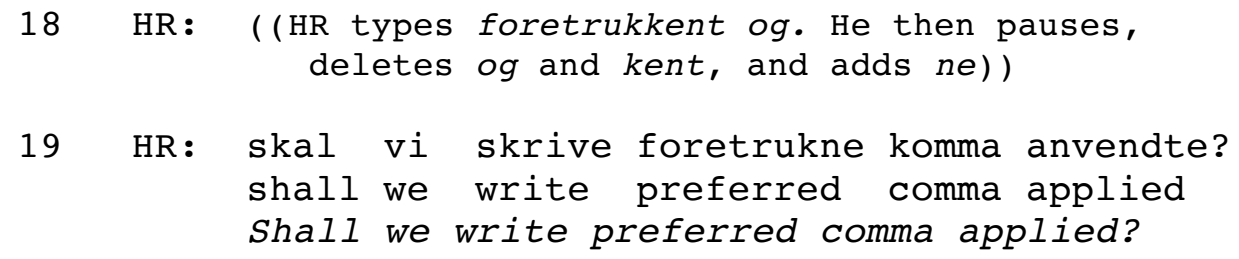


Although HR previously passed the opportunity to discuss CEO's proposal by displaying his prompt agreement, he now changes the course of action. As he starts revising the document, he deviates from the original plan (i.e. the proposal made by $\mathrm{CEO):} \mathrm{he} \mathrm{changes} \mathrm{the} \mathrm{wording} \mathrm{from} \mathrm{what} \mathrm{CEO} \mathrm{has} \mathrm{suggested} \mathrm{--} \mathrm{foretrukkent}$ ("preferably") -- to foretrukne ("preferred") (1. 18). Having physically implemented most of this change, he then verbalizes his modified proposal, which is to write foretrukne, anvendte ("preferred, applied") instead of foretrukne anvendte ("preferably applied") (1. 19). He frames his proposal in the same way as CEO did, using skal vi ("shall we"). Unlike CEO's original proposal, however, HR does not indicate an upcoming discussion between him and CEO: his gaze is fixed on the notebook computer, and his posture and hand movements show his continuous involvement in the typing process. Additionally, HR's proposal displays his strong entitlement due to the typing behaviour that preceded his verbal proposal.

We argue that CEO's orientation to the equal entitlement might have impacted the way HR showed his entitlement in making his counter-proposal. Moreover, when CEO hesitates and possibly projects an upcoming disagreement (1.20), HR enhances his entitlement by continuing to implement the change he has proposed (1. 21). It is not clear 
whether HR's embodied action here indicates that he has already made an autonomous decision, or that he is further pursuing CEO's acceptance via the visualization of the idea. Either way, the point to be made here is that HR chooses to pursue the implementation of his modified proposal instead of working with CEO's display of the problems involved in the proposal by presenting an alternative course of action (Davidson, 1984). He even marks a temporary completion of typing by leaning back on his chair and crossing his arms (1. 22). Seeing this, CEO accepts HR's proposal (1.23) - although he does so weakly.

Above we saw how HR modified CEO's initial proposal and claimed his strong entitlement when launching a second proposal. However, HR's behaviour seemed to be heavily influenced by the way CEO framed his initial proposing action. Recall how CEO marked his and HR's roles as co-discussants during his initial proposal. Similarly, CEO's entitlement to make a proposal was marked as equal as that of HR. This might have made it easier for HR to launch a modified second proposal. Hayano (in press) and Heinemann et al. (in press) discuss the fact that there is a congruency in the ways participants display the degree of their entitlement. This may be the case here: HR's proposal design (with high entitlement) was the response to CEO's initial proposal design (with low entitlement). So does this mean that if the first proposal is launched with the proposer's high entitlement, the co-participant's second proposal will be launched with low entitlement? We explore this question with the next excerpt.

In the following segment, CEO suggests extending the list of strategic goals by adding offentligheden ("the public") to kunder og samarbejdspartnere ("customers and partners"). We see how CEO's strong entitlement and his role as a decision-maker are 
consistently maintained throughout the sequence, even during HR's modified second proposal.

\section{Excerpt (5)}

1 CEO: til kunder, (.) komma samarbejdspartnere og

to customers(.) comma partners and

To customers, comma partners and

2

Offentligheden.

public_the.

the public.

3

(2.4) ((CEO continues to look at CP; HR deletes a word?))

4 CEO : det d- laver vi faktisk oss'.

this d- do we actually àlso

This we actually also do.

5 HR: ja.

Yes. (1.2) ((HR stays still with his hands by his side, not on
the keyboard))

The segment begins with CEO's proposal to add the term "offentligheden" ("the public") to a sentence in the document (11. 1-2). In so doing, he uses a direct statement, which displays his strong entitlement. However, his proposal is followed by 2.4 seconds of silence (1. 3), and CEO recompletes his turn in line 4. Here, by providing information that accounts for his proposal, CEO does not only make HR's responsive action conditionally relevant - he also increases the justifiability of the proposal. Immediately following this, HR provides confirmation (1. 5). However, HR's response does not indicate more than mere alignment with CEO's previous turn; he does not verbally elaborate on his agreement, and his bodily behaviour does not indicate that he is about to type anything (1.6). The lack of affiliative actions could indicate an upcoming disagreement (Asmuß, in press); and what HR does next is to launch an insertion sequence to clarify his word choice. By doing so, HR challenges CEO's original proposal 
that he is about to type something. But he deviates from this course of action (i.e., he adjusts his bodily location) as he asks the question. In addition his gaze shifts from the notebook computer to CEO (1. 7), thereby inviting a mutual gaze, which makes the imminent discussion an alternative next event other than typing. In other words, HR allows the possibility that the question could turn into a discussion rather than requiring mere clarification.

The point here is that HR still aligns with CEO's previously claimed entitlement. This is seen in the fact that: 1) HR underlines his role as the person doing the typing (as opposed to being a co-discussant) by saying Skal jeg skrive ("Shall I write"); and 2) HR mitigates his position on the proposal by listing his idea (myndigheder (“authorities")) first, followed by the term proposed by CEO (offentligheden ("the public")). In general, the word that is located immediately before the next turn tends to be accepted more easily, and that is what CEO does next in line 8. Despite the "innocent" appearance of HR's question - HR seems to be asking for a word choice clarification - CEO apparently regards HR's action as making a modified proposal that challenges his initial proposal, and rejects it. HR's utterance is framed as a question about which term fits better, something to which CEO can respond by selecting one over the other (e.g., offentligheden ("the public")). Nonetheless, CEO begins his utterance with $N e j$ ("No") (1. 8). CEO further attempts to provide an account for his decision (11. 10-11), thereby demonstrating that he regards HR's previous utterance as a challenge to his initial proposal. As soon as HR hears CEO's rejection, he shifts his gaze back to the computer and resumes typing (1. $8)$.

Like excerpt 4 , this example shows that the way CEO launched the original proposal had a dynamic impact on the subsequent actions of the participants. The 
entitlement claimed by CEO at the beginning of the sequence was confirmed by HR in the way he launched his proposal; and was then reconfirmed by CEO, who frankly (emphasized and latched onto HR's turn) rejected HR's modified second proposal. The participants' alignment with each other in terms of entitlement was seen during the problematic event of launching a modified second proposal, and it is in this sustained and mutually oriented hierarchy of entitlement that they reached the final decision on future action.

\section{Conclusion}

The proposals in our collected sequences have taken various formats, with which the proposer displayed his understanding of the degree of his entitlement. The proposal with a positive interrogative displayed low entitlement (excerpt 4), while that of a negative interrogative displayed high entitlement (excerpts 1 and 2). The direct voicing of an alternative formulation (excerpt 3) displayed the highest entitlement. As a proposal frequently displays the proposer's degree of entitlement, it becomes relevant that the second speaker also demonstrates his/her orientation to it. Thus, proposing a future action makes relevant two kinds of orientation by the co-participant: 1) acceptance or rejection of the proposal; and 2) acceptance or rejection of the speaker's entitlement to make or accept the proposal. It was shown that participants in interaction make use of various resources in proposal sequences in order to show an orientation to these aspects. In proposal sequences that are accepted straightaway and not prolonged by post-expansions or modified second proposals (as seen in excerpt 1), co-participants regularly display an acceptance of both the content of the proposal and the entitlement displayed during the proposal. In terms of institutional roles, the predefined institutional roles of the CEO and 
the HR manager were not challenged or redefined, but acknowledged and confirmed: the CEO was hierarchically superior and made the proposal, while the HR manager was hierarchically inferior (performing the editing work), and accepted and performed the relevant next action. Thus, while institutional roles in this case were confirmed, the excerpt still illustrated that institutional roles are local achievements and are subject to continuous renegotiation throughout interaction.

In proposal sequences that are followed by post-expansions, participants may take the opportunity to deal with questions of entitlement in the expansion sequence. In the cases analyzed (excerpts 2 and 3), co-participants used an expansion to mark independent access to the issue proposed, thereby challenging the display of entitlement in the initial proposal. Thus a proposal expansion enabled the participants to show their understanding of their institutional roles and to renegotiate these roles before final acceptance of the proposal was given.

In proposal sequences that were met with a modified proposal, the participant making the modified proposal displayed a different understanding regarding the content of the original proposal. Moreover, by suggesting a modified proposal, he displayed his own entitlement to make a proposal, thereby inviting the initiator of the first proposal to renegotiate this entitlement. The analysis also indicated a relation between the entitlement displayed in the initial proposal and the subsequent proposal: the degree of entitlement marked in the later proposal matched the degree of entitlement displayed in the original proposal.

In an institutional setting like a formal strategy meeting, participants often have externally defined roles in relation to the goal of the meeting. Thus, one could assume that the mere acceptance or rejection of a proposal would be the most central activity. 
However, this study shows that meeting participants use proposal sequences to define and (re)negotiate questions of entitlement. In line with the notion of interaction as being both context-shaped and context renewing (Heritage, 1984: 242; Sacks et al., 1974: 699f), contextual features like institutional roles that might be interpreted as static, external entities actually seem to be interactive and local achievements in talk instead.

The aspect of entitlement also becomes relevant with regard to aligning and affiliating with a proposal. In excerpts 2 and 3 participants immediately aligned with the proposal, but no full acceptance was given and a post-expansion was initiated. Full acceptance - the implementation of the proposal - was granted only after the participants had successfully negotiated questions of entitlement in the post-expanded sequence. Thus, the study supports previous studies on alignment and affiliation that argue that the display of alignment without affiliating actions might indicate problems in complying with first actions (Stivers et al., in press; Asmuß, in press).

Another aspect that should be highlighted in the present study is the use of multimodal resources by the participants in orienting to aspects of content and entitlement. Here, the use of mutual gaze, orientation to the computer projection, and the actual typing of the document, together with the use of verbal resources, were crucial in the display of (dis)-alignment and (dis)-affiliation with the proposal and its entitlement. This is in contrast to some of the aforementioned studies, which focus mostly on linguistic devices (Craven and Potter, 2010; Heinemann, 2006). Thus, the current study may help to exemplify the relevance of conducting multimodal analysis of face-to-face interaction in ordinary and institutional settings.

The point made above leads us to discuss yet another final contribution of the study, which lies in its suggestion regarding studying "ordinary" workplace data as 
opposed to "special" settings. Many of the multimodal studies of interaction carried out so far have focused on "special" settings (Mondada, 2007 (video conference); Clark and Pinch, 2010 (preverbal service encounter); Heath and Luff, 2010 (bidding at auctions)). A study like the current one shows that there is an enormous complexity in the resources available even in so-called "simple settings". Our study indicated that the physical location of (and access by participants to) technological devices might serve as additional resources for the negotiation of institutional roles. Likewise, the bodily orientation of the participants, which is largely defined by physical aspects of the meeting place (e.g. tables, chairs, and other technical equipment), constitutes a resource for negotiating the shared understanding of the participants in an institutional setting. Without careful consideration of the array of resources that are available to the interactants, there is a risk that we will fail to understand the full complexity of human action. Moreover, by including the use of today's common artifacts at meetings such as computers and computer projections in our analysis, we can enhance our knowledge of the potential affordances and constraints related to the use of technical equipment in meeting interactions. The current study might be a small brick in building up a thorough understanding of these aspects of human interaction. 


\section{References}

Asmuß, B. (in press) 'Proposing Shared Knowledge as a Means of Pursuing Agreement', in T. Stivers, M. Lorenza, and J. Steensig (eds.), The Morality of Knowledge in Conversation. Cambridge: Cambridge University Press.

Asmuß, B. (2007) 'What Do People Expect from Public Services? Requests in Public Service Encounters', Journal of Language and Communication Studies 38: 65-83.

Asmuß, B. and Svennevig, J. (2009) 'Meeting Talk: An Introduction', Journal of Business Communication 46(1): 3-22.

Boden, D. (1994) The Business of Talk. Organizations in Action. Cambridge, UK: Polity.

Clark, C. and Pinch, T. (2010) 'Some major organizational consequences of some "minor" organised conduct: evidence from a video analysis of preverbal service encounters in a showroom retail store.', in Llewellyn, N. \& Hindmarsh J. (eds.), Organisation, interaction and practice. Studies in Ethnomethodology and Conversation Analysis. Cambridge: Cambridge University Press, pp. 140-171.

Craven, A. and Potter, J. (2010) 'Directives: Entitlement and Contingency in Action', Discourse Studies 12(4): 419-442.

Curl, T. and Drew, P. (2008) 'Contingency and Action: A Comparison of Two Forms of Requesting', Research on Language \& Social Interaction 41(2): 129-153.

Davidson, J.A. (1984) 'Subsequent Versions of Invitations, Offers, Requests, and Proposals Dealing with Potential or Actual Rejection', in J.M. Atkinson and J. Heritage (eds.) Structures of Social Action: Studies in Conversation Analysis, pp. 57-101. Cambridge: Cambridge University Press.

Depperman, A., Mondada, L., and Schmitt, R. (in press) 'Planned and Contingent Action: a Detailed Analysis of a Meeting's Pause', Journal of Pragmatics.

Garcia, A. (1997) 'Interactional Constraints on Proposal Generation in Negotiation Hearings: A Preliminary Investigation', Discourse \& Society 8: 219-47.

Hayano, K. (in press) 'Giving support to the claim of epistemic primacy: yo-marked assessments in Japanese.', in T. Stivers, M. Lorenza, and J. Steensig (eds.) The Morality of Knowledge in Conversation. Cambridge: Cambridge University Press.

Heath, C. and Luff, P. (2010) 'Orders of bidding: organising participation in auctions of fine art and antiques.', in Llewellyn, N. and Hindmarsh J. (eds.), Organisation, interaction and practice. Studies in Ethnomethodology and Conversation Analysis. Cambridge: Cambridge University Press, pp. 119-139.

Heinemann, T. (2009) 'Participation and exclusion in third party complaints', Journal of Pragmatics 41: 2435-2451.

Heinemann, T. (2006) 'Will You or Can't You?': Displaying Entitlement in Interrogative Requests', Journal of Pragmatics 38: 1081-1104.

Heinemann, T., Lindström, A. and Steensig, J. (in press) 'Addressing epistemic incongruence in question-answer sequences through the use of epistemic adverbs', in T. Stivers, M. Lorenza, and J. Steensig (eds.), The Morality of Knowledge in Conversation. Cambridge: Cambridge University Press.

Heritage, J. (1984) Garfinkel and Ethnomethodology. Cambridge: Polity Press.

Houtkoop-Steenstra, H. (1987) Establishing Agreement: An Analysis of Proposal Acceptance Sequences. Dordrecht/Providence, R.I.: Foris Publications.

Lindström, A. (2005) 'Language as social action: A study of how senior citizens request assistance with practical tasks in the Swedish home help service.' In A. Hakulinen 
and M. Selting (eds.), Syntax and lexis in conversation (pp. 209-230). Amsterdam: John Benjamins.

Lindström, A. (1999) Language as social action: Grammar, prosody, and interaction in Swedish conversation. (Skrifter utgivna av Institutionen för nordiska språk, Uppsala universitet 46.) Diss. Uppsala.

Lindström, A. and Heinemann, T. (2009) 'Good Enough: Low-Grade Assessments in Caregiving Situations.' Research on Language and Social Interaction, 42(4): 309328.

Maynard, D. (1984) Inside Plea Bargaining: The language of negotiation. New York: Plenum.

Mondada, L. (2007) 'Operating Together through Videoconference: Members' Procedures for Accomplishing a Common Space of Action' in S. Hester and D. Francis, (eds.), Orders of Ordinary Action, pp. 51-67. Aldershot: Ashgate.

Nevile, M. and Rendle-Short, J. (2009) 'A Conversation Analysis View of Communication as Jointly Accomplished Social Interaction: An Unsuccessful Proposal for a Social Visit.' In M. Haugh and A. Liddicoat (eds.), Conceptualizing Communication. Special Issue, Australian Journal of Linguistics 29: 75-89.

Oshima, S. (2009) Beauty and Consensus: Practices for Agreeing on the Quality of the Service in Client-Professional Interactions. Dept. of Communication Studies. The University of Texas at Austin, Austin.

Pomerantz, A. (1984) 'Agreeing and Disagreeing with Assessments: Some Features of Preferred/Dispreferred Turn Shapes.' In J.M. Atkinson and J. Heritage (eds.), Structures of Social Action. Studies in Conversation Analysis, pp. 57-101. Cambridge: Cambridge University Press.

Pomerantz, A. and Denvir, P. (2007) 'Enacting the Institutional Role of Chairperson in Upper Management Meetings: The Interactional Realization of Provisional Authority.' In F. Cooren (ed.), Interacting and organizing: Analyses of a management meeting, pp. 31-51. Mahwah, NJ: Lawrence Erlbaum.

Raymond, G. (2003) 'Grammar and social organization: Yes/no interrogatives and the structure of responding', American Sociological Review 68: 939-967.

Sacks, H., Schegloff, E.A. and Jefferson, G. (1974) 'A Simplest Systematics for the Organization of Turn-taking for Conversation', Language 50(4): 696-735.

Steensig, J. (in press) 'Affiliation and Alignment.' In Chapelle, C.A. (ed) Encyclopedia of Applied Linguistics. Blackwell Publishing.

Steensig, J. and Drew, P. (2008) 'Introduction: Questioning and Affiliation/Disaffiliation in Interaction', Discourse Studies 10(1): 5-15.

Stivers, T. (2008) 'Stance, Alignment, and Affiliation During Storytelling: When Nodding Is a Token of Affiliation', Research on Language \& Social Interaction 41(1): 31-57.

Stivers, T., Mondada, L., and Steensig, J. (in press) 'Knowledge, Morality and Affiliation in Social Interaction.' In T. Stivers, M. Lorenza, and J. Steensig (eds.), The Morality of Knowledge in Conversation. Cambridge: Cambridge University Press.

Stivers, T., and Sidnell, J. (2005) 'Introduction: Multimodal Interaction', Semiotica, 156(1/4): 1-20.

Streeck, J. (2002) 'A Body and Its Gestures', Gesture, 2(1): 19-44.

Vöge, M. (2010) 'Local identity processes in business meetings displayed through laughter in complaint sequences', Journal of Pragmatics 42: 1556-1576. 


\section{Author biographies}

Birte Asmuß is an Associate Professor at the Department of Business Communication at Aarhus University, Denmark. Her research area is talk-in-interaction in various institutional settings including formal and informal meeting talk, performance appraisal interviews and public service talk. She is interested in topics such as affiliation and alignment, entitlement and multimodality; and in activity types such as requests and proposals.

Sae Oshima is a Visiting Assistant Professor at the Department of Business Communication at Aarhus University, Denmark. She explores the meanings of professional communication through microanalysis of workplace interactions, including beauty-related service encounters and internal strategy meetings. The objectives of her research include pursuing certain business outcomes as interactional products, as well as proposing implications for training in various workplaces.

Birte Asmuß (corresponding author)

Department of Business Communication Aarhus University

Fuglesangs Allé 4, DK-8210 Aarhus V

Denmark

T: $+45-89-48-65-90$

F: $+45-86-15-77-27$

E: bas@asb.dk

\author{
Sae Oshima \\ Department of Business Communication \\ Aarhus University \\ Fuglesangs Allé 4, DK-8210 Aarhus V \\ Denmark \\ $\mathrm{T}:+45-89-48-67-41$ \\ F: +45-86-15-77-27 \\ E: soshima@asb.dk
}

